\title{
Does Mode of Access Make a Difference? Mobile Learning and Online Student Engagement
}

\author{
Sarah Nichter \\ University of the Cumberlands
}

\begin{abstract}
Even though student use of mobile devices for educational purposes has increased in recent years, the research on the possible impact on student success or engagement has been minimal. This study investigated the impact of mobile device use on student engagement and student success in online courses. The theory of Self-Regulated Learning (SRL) was a foundation for understanding and measuring engagement behaviors of online students. The Online SelfRegulated Learning Questionnaire (OSLQ) was the basis of the survey instrument. Participants were categorized into three groups of mobile device use (low, moderate, high). These three groups were used for comparison in each of the research questions. The research questions ask what impacts mobile learning has on student engagement, as measured with SRL; what impact mobile learning has on the SRL constructs of environment structuring, task management, and time management; and what associations mobile learning might have with student success and persistence. The ANOVA showed that mobile learning had a moderate impact on engagement for students in the high group. Students in each group engaged in environment structuring behaviors more than task strategies or time management behaviors. Students in the moderate and high groups engaged in task strategies more than the low group. Students in the high group engaged in time management behaviors more than the other groups. The Crosstab analysis did not show an association between levels of mobile learning and course grade or persistence. These findings have positive implications for online pedagogy and course design.
\end{abstract}

Keywords: mobile learning; online learning; student engagement; self-regulated learning; student success

Nichter, S. (2021). Does mode of access make a difference? Mobile learning and online student engagement. Online Learning, 25(3), 5-17. doi:10.24059/olj.v25i3.2848 
Mobile devices have become commonplace in our culture, with users finding many applications beyond basic functions. Pew Research reports that smartphone ownership by U.S. adults has now reached $85 \%$, with $95 \%$ of adults aged $18-49$ owning smartphones, with about half of the same population also owning a tablet (2021). As ubiquitous as these devices are, it seems a natural progression of acceptance that students are using their mobile devices for educational purposes. Longitudinal data have established the intention of students to use their mobile devices as an education tool (Capranos, \& Dyers, 2020; Gierdowski, 2019; Magda et al., 2020). Currently, most students surveyed noted they want to be able to use their mobile devices for their coursework and that mobile-friendly websites and courses are extremely important (Capranos, \& Dyers, 2020; Gierdowski, 2019; Magda et al., 2020).

Even with this growth, the research on the impact of mobile device use has been sparse. Early research on mobile devices, smartphones, or tablets, focused on student readiness to use these devices for educational purposes, then moved to study how mobile devices might mediate learning (Martin et al., 2013; Puzziferro, 2008; Sharples et al., 2016). Still, little of the research investigated the influence of mobile device use on students' academic success. This present study focuses on the possible impact of mobile device use on students' engagement and academic success in online courses. Knowing more about student behavior with mobile devices and its impact on engagement and success can influence online pedagogy, course design, and student preparation.

What follows is a brief review of the relevant literature that will establish the theoretical framework for this study. Research questions guiding the inquiry will follow and an explanation of the research methods, the results, and a discussion of the findings.

\section{Review of Literature}

Research on mobile device application and usage has increased over the past decade. During this time, two parallel perceptions of mobile learning developed, while the theory of mobile learning itself has also evolved. Early approaches to mobile device use focused on and established student readiness for mobile use (Cheon et al., 2012; Martin et al., 2013; Vilkonis et al., 2013). Around 2015, researchers began to focus on mobile device use as a mediator for learning (Sharples et al., 2016), such as the self-regulatory and reflective practice with learning analytics making students aware of their behavior (Tabuenca et al., 2015).

\section{Mobile Learning}

These evolutions and conceptual changes concerning mobile device use led to the development of Mobile Learning theory. Mobile Learning theory is in its infancy, and defining Mobile Learning is challenging as several perspectives compete for dominance (Grant, 2019). A notable shift in the theory development occurred as researchers began to stress that the technology employed is not mobile learning, but rather that mobile learning is merely a method of accessing technology (El-Hussein \& Cronje, 2010; Sharples et al., 2016). A theory of mobile learning must be significantly different from other theories of learning situated in physical environments; it must encompass formal, informal, and non-formal learning; it must theorize learning as a constructive and social process; and it must analyze learning as personal, contextual, and mediated by technology (Sharpels et al., 2016). Mobile Learning is connected to online learning but is not confined to the traditional barriers of online education and traditional education. Even with the flexibility of online education, students are still tethered to a place with desktop computers and even laptops. Few online learners find it ideal to engage in their courses with a laptop while waiting for public transit, and they may not have a computer available when 
time offers the opportunity to engage in their classes. However, a mobile device offers an online student the opportunity to ask a question in the class or read course content during a lunch break or while waiting for the bus. Mobile Learning centers on the fluidity of learning through different contexts, allowing for "anytime, anywhere" access and learning.

These assertions about mobile learning can be brought together in this definition: mobile learning is situationally based on the mobility of learners and learning contexts, allowing for fluidity of personal learning in time, content, and context, and mediated through technology (ElHussein \& Cronje, 2010; Sharples et al., 2016).

Research investigating and applying mobile learning has progressed along two main channels: mobile learning as support to traditional learning and mobile learning as the mediator of learning. 2010 became a notable year for mobile technologies and its researchers, as tablet popularity boomed, and researchers were eager to test its educational possibilities. A notable focus in research on mobile learning after 2010 was on student readiness or student motivators and behaviors for learning in the mobile environment (Cheon et al., 2012; Gikas \& Grant, 2013; Khaddage et al., 2016; Liu et al., 2010; Martin et al., 2013; Rossing et al., 2012; Vilkonis et al., 2013). Among these studies, common motivating factors or benefits of mobile learning expressed by students were quick and easy access to information, course content, and learning resources; the ability to upload content; participating in discussion boards; and the immediacy of contact between students and with faculty (Gikas, \& Grant, 2013; Martin et al., 2013; VázquezCano, 2014).

The transition from mobile learning as support for learning to mobile learning as a mediator of learning signifies a conceptual change of mobile learning. Such a shift influences the applicability and development of mobile learning within institutions and the broader higher education landscape. Mobile learning is linked with e-learning. It encapsulates the learning design best practices through the online environment; after all, education is essentially communication, and mobile learning is a new avenue for communication. The development of learning analytics and what it can show of students' anytime, anywhere engagement is evidence of this conceptual change. Learning analytics has been tested as not just a tracking tool but a selfreflective and regulatory tool for learners (Tabuenca et al., 2015). When teachers' estimates of time for a task were compared with students' time-logs for the task, Tabuenca et al. (2015) found that students' time management showed significant improvement by being aware of how much time they were or were not spending on learning activities occurring through mobile learning.

A notable absence in the literature on Mobile Learning is a connection to an established theory of learning and empirical research of the impact of Mobile Learning on learning and academic success. If we consider mobile devices as educational tools, a conceptual framework including learning theory must be tested to establish applicability and credibility. A concentrated group of researchers has tested the applicability of Self-Regulated Learning theory with Mobile Learning to develop such a framework.

\section{Self-Regulated Learning}

Self-Regulated Learning (SRL) theory grew from the research of Zimmerman (2008, 2001) and Pintrich $(2004,1999)$ and focused on cognitive, motivational, and behavioral skills of

learners to become masters of their own learning. SRL transforms this focus into three categories that can be observed and measured: cognitive learning strategies, self-regulatory strategies to control cognition, and resource management strategies (Pintrich, 2004, 1999; Zimmerman, 2008, 2001). Zimmerman (2001) defines the theory as "neither a mental ability nor an academic performance skill, self-regulation refers instead to the self-directed process through which 
learners transform their mental abilities into task-related academic skills. This approach views learning as an activity that students do for themselves in a proactive way" (p. 1).

The two most relevant assumptions of SRL for online learning and mobile learning are the potential for control assumption and the assumption that SRL activities are "mediators between personal and contextual characteristics and actual achievement or performance" (Pintrich, 2004, p.388). Viewing online student behavior through the lens of SRL highlights how students regulate their motivation, cognition, and behaviors to benefit their academic success. For example, many students cite a reason for choosing online classes is that online is a better opportunity to regulate their time and academic abilities in the learning environment.

The research on measuring SRL within the context of online learning is still minimal but noteworthy. Puzziferro's (2008) study began to establish the impact of SRL behaviors on online students' academic performance. Puzziferro surveyed a wide range of fully online community college students and found the study environment, time management, and effort regulation were significant to these students' academic performance in general, and that effort regulation was significant for course grade (2008). These results suggest that students who received higher final course grades were more likely to manage their study time (the planning, scheduling, and execution) and their study environment, further suggesting that these students could more effectively match their study habits to their study style.

In Cho \& Shen's research (2013), intrinsic goal orientation and academic self-efficacy were positively associated with and mediated by the SRL strategies of metacognitive regulation, effort regulation, and interaction regulation. Additionally, the total amount of time students spent in the LMS plus their effort regulation together were significant positive predictors of the course grade (Cho \& Shen, 2013).

Broadbent and Poon's (2015) systematic review of the literature on SRL strategies and academic achievement brought to light several categories of SRL that proved significant in the online learning environment. Among the 12 studies included in the analysis, the SRL categories of time management, effort regulation, metacognition, and critical thinking had positive correlations with academic achievement (Broadbent \& Poon, 2015). The follow-up to this study compared fully online and blended learners' SRL strategies and academic success. For both groups, time management, elaboration, and effort regulation were the most used SRL strategies (Broadbent, 2017). For fully online learners, the use of elaboration, organization, metacognition, time management, and effort management were significantly higher than for blended learners; peer learning and help-seeking strategies occurred at a higher rate for blended learners (Broadbent, 2017). These results suggest that the online environment requires students to implement time management and effort regulation more than other learning environments and contexts. Additionally, Broadbent's (2017) study found that only effort regulation and time management positively predicted course grades for online students. Despite this limited body of research, these categories continue to show evidence of positively impacting students' academic success in the online environment.

Limited research exists testing the impact of SRL in the mobile learning environment. Much of the theory application has been with behavior theories such as the Technology Acceptance Model and the Theory of Planned Behavior. Sha, Looi, Chen, and Zhang (2011) note the sparse theory development for mobile learning and SRL across different fields. Sha et al. (2011) state, "mobile learning environments presumably provide a means by which students can exercise agency to control their own [behavior] and cognition" (p. 367). SRL is an applicable theory because the "knowledge and skills of SRL can be seen as a precursor to mobile 
learning, as well as one of the desired outcomes of mobile learning given that the design and implementation of mobile learning systems fit the principles of SRL" (p. 368).

\section{Student Success and Engagement}

Any discussion about student success online is also a discussion of engagement. Student engagement performs a distinct role in the online learning environment since it requires a different set of behaviors from online learners. That student behaviors can be changed or influenced is foundational for any discussion of student engagement, and even more so for online learners. The term student engagement is used widely in the literature for multiple aspects of higher education. Hu and $\mathrm{Ku}$ (2002) assert that student engagement is "the quality of effort students themselves devote to educationally purposeful activities that contribute directly to desired outcomes" (p. 555). Much of the research on engagement and higher education still centers on the traditional contexts. Dumford \& Miller (2018) note this gap in the literature as a motivating factor for their research on the engagement of students who access their online classes at varying levels. Using NSSE engagement measures, they found that first-year students increased the time spent on quantitative reasoning with the more online class they took, and more online classes were overall related to more engagement (2018). However, for seniors in the study, time spent on quantitative reasoning decreased with more online classes they took and decreased with other measures of engagement (2018). However, NSSE data does not measure self-directed or self-regulatory behaviors such as students' choices about how often they engage with online courses and other behaviors to adapt study skills to the environment.

Similar to engagement, research on student success is vast and varied even within higher education. When focusing student success on academic success at the student level, student success is conceptualized as the interaction of these three categories: grade performance, completion, and satisfaction (Puzziferro, 2008). The connectedness of these three categories is essential to a complete picture of student success. A trend in recent research has been to use the GPA as a single measure of student success; however, such an isolating view can leave the researcher with an incomplete understanding. Additionally, focusing on just completion can ignore other significant academic information since successful students may pace their course completion differently, and successful students also leave by transfer, stop-out, or pause-out. Student satisfaction measured alone could result in meaningless information since satisfaction is typically a self-reported measure that can be effect by a broad number of factors. Therefore, measures of student success that consider more than one of these categories can provide a complete understanding of student success.

This study brings together the research on Mobile Learning, Self-Regulated Learning, and student success to investigate the impact of Mobile Learning on the engagement and success of students in online classes. Student success online is a composite of the tools available to students, the flexibility online classes can afford to learners, and the self-regulatory and selfaware behaviors they engage in while learning.

Research Questions

1. What impact does mobile learning have on student engagement in an online class?

2. What is the extent of the impact of mobile learning on Self-Regulated Learning constructs?

3. How does mobile learning affect student success online? 


\section{Population and sampling}

\section{Methods}

The population for the study was undergraduate students at one mid-sized university taking fully online courses $(n=1,641)$. Convenience sampling was used, and all actively enrolled students in the population had the opportunity to participate by choosing to complete the survey. The survey instrument was distributed to students in the population during the Spring semester (March 2020) to report on their current activities in their online class. In total, 162 students opted-in to participate by taking the survey.

\section{Survey}

The Online Self-Regulated Learning Questionnaire (OSLQ) was used for the survey instrument, which uses a 5 point Likert-type scale with responses ranging from strongly agree (5) to strongly disagree (1). The short form of the OSLQ was chosen because six Self-Regulated Learning constructs for the online environment organize it: environment structuring, goal-setting, help-seeking, task strategies, time management, and self-evaluation (Barnard et al., 2008). Eleven items from the OSLQ were chosen to measure the SRL constructs of environment structuring, task strategies, and time management. These constructs proved to be the most relevant and were most likely to show significance based on previous research (Alanazi \& Brown, 2016; Barnard-Brak et al., 2010; Cho \& Shen, 2013; Puzziffero, 2008). Several demographic questions were added to the survey instrument, as well as questions about mobile device use.

\section{Data Collection and Analysis}

The survey instrument measured mobile learning usage with self-reported responses on the frequency of course access with a mobile device (smartphone or tablet) and the activities engaged in via a mobile device. Respondents were grouped by levels of mobile learning use based on the frequency of course access with a mobile device: Low (accessed 1-3 times a week), Moderate (accessed 4-8 times a week), and high (accessed 9+ times a week). The three mobile learning levels were independent variables for each of the three research questions, with the summed SRL measures, course grades, and course persistence as dependent variables. One-Way Analysis of Variance (ANOVA), Tukey post hoc tests, and Chi-Square Crosstabs analysis were used to analyze the data for the research questions. During the analysis, three constructs of SRL were isolated for analysis: environment structuring, task strategies, and time management.

\section{Demographics}

\section{Results}

Of the 162 respondents, $40(24.7 \%)$ of the respondents reported their age as 18-25 years; $59(36.4 \%)$ reported their age as 26-35 years; 43 (26.5\%) reported their age as 36-45 years; 18 $(11.1 \%)$ reported their age as 46-55 years; $2(1.2 \%)$ reported their age as over 55 years. These age demographics are representative of the overall online student population of the institution.

An initial question on the survey asked students to indicate how often they accessed their online course with a mobile device: 1-3 times a week, 4-8 times a week, or 9 or more times a week. This categorized respondents into three mobile learning usage groups: low, moderate, and high (Table 1). The groups were the basis of comparison for each research question. 
Table 1

Mobile Learning Group Membership by Level of Mobile Use

\begin{tabular}{llcc}
\hline & & Frequency & Percent \\
\hline \multirow{3}{*}{ Valid } & 1-3 times weekly & 70 & 43.2 \\
\cline { 2 - 4 } & 4-8 times weekly & 55 & 34.0 \\
\cline { 2 - 4 } & 9 or more times weekly & 37 & 22.8 \\
\cline { 2 - 4 } & Total & 162 & 100.0
\end{tabular}

Note. "times weekly" represents the number of times a student engaged in the online course via a mobile device.

\section{Results by Research Question}

Research question 1 tested the impact of mobile learning on student engagement in an online class. The one-way ANOVA showed a statistically significant difference between the three levels of mobile learning use, with SRL scores as the measure of engagement $(F(2,159)=$ $6.570, p=.002, d=.275)$. The Tukey post hoc test revealed that the SRL scores for the low group were significantly lower than the high group (HSD $=-4.581, p=.001, d=.719)$. The variation between groups was not significantly different between the other group comparisons.

Research question 2 tested the extent of the impact of mobile learning on the SelfRegulated Learning constructs of environment structuring, task strategies, and time management. Three separate one-way ANOVA were conducted for each SRL construct. The ANOVA with environment structuring as the dependent variable did not show significant variance between the groups of mobile learning use. The ANOVA with task strategies showed a statistically significant difference between groups $(F(2,159)=8.065, p=.000, d=.303)$, as well as a statistically significant difference between groups for time management $(F(2,159)=3.448, p$ $=.034, d=.202$ ). A Tukey post hoc analysis was performed for both task strategies and time management (Table 2). The analysis showed that the task strategy construct scores for the low group were significantly lower than the scores for the high group (HSD= -

$2.624, p=.000, d=.796$ ). The scores for the moderate group were also significantly lower than the scores for the high group (HSD $=-1.681, p=.040, d=.494)$. The analysis showed that the time management construct scores for the low group were significantly lower than the scores for the high group $(\mathrm{HSD}=-1.293, p=.026, d=.505)$.

Table 2

Tukey HSD, between groups comparison, SRL Task Strategies and Time Management

\begin{tabular}{|c|c|c|c|c|c|c|c|c|}
\hline \multirow[b]{2}{*}{$\begin{array}{l}\text { Dependent } \\
\text { Variable } \\
\end{array}$} & \multirow[b]{2}{*}{$\begin{array}{l}\text { (I) Mobile } \\
\text { Use }\end{array}$} & \multirow[b]{2}{*}{ Mobile Use } & \multirow{2}{*}{$\begin{array}{c}\text { Mean } \\
\text { Difference } \\
(\mathbf{I}-\mathbf{J})\end{array}$} & \multirow[b]{2}{*}{$\begin{array}{c}\text { Std. } \\
\text { Error }\end{array}$} & \multirow[b]{2}{*}{ Sig. } & \multicolumn{2}{|c|}{$\begin{array}{c}95 \% \text { Confidence } \\
\text { Interval } \\
\end{array}$} & \multirow[b]{2}{*}{$d$} \\
\hline & & & & & & $\begin{array}{l}\text { Lower } \\
\text { Bound }\end{array}$ & $\begin{array}{l}\text { Upper } \\
\text { Bound }\end{array}$ & \\
\hline \multirow{6}{*}{$\begin{array}{l}\text { SRL Task Strat } \\
\text { Score }\end{array}$} & Low & Moderate & -0.943 & .579 & .237 & -2.31 & .43 & .301 \\
\hline & & High & $-2.624^{* *}$ & .653 & .000 & -4.17 & -1.08 & .796 \\
\hline & Moderate & Low & 0.943 & .579 & .237 & -.43 & 2.31 & .301 \\
\hline & & High & $-1.681^{*}$ & .684 & .040 & -3.30 & -.06 & .494 \\
\hline & High & Low & $2.624^{* *}$ & .653 & .000 & 1.08 & 4.17 & .796 \\
\hline & & Moderate & $1.681^{*}$ & .684 & .040 & .06 & 3.30 & .494 \\
\hline
\end{tabular}




\begin{tabular}{lccccccccc}
\hline SRL \\
Time Mgmt Score & Low & Moderate & -0.405 & .437 & .624 & -1.44 & .63 & .169 \\
& & High & $-1.293^{* *}$ & .493 & .026 & -2.46 & -.13 & .505 \\
& \multirow{2}{*}{ Moderate } & Low & 0.405 & .437 & .624 & -.63 & 1.44 & .169 \\
& & High & -0.887 & .515 & .200 & -2.11 & .33 & .376 \\
& \multirow{2}{*}{ High } & Low & $1.293^{* *}$ & .493 & .026 & .13 & 2.46 & .505 \\
& & Moderate & 0.887 & .515 & .200 & -.33 & 2.11 & .376 \\
& & & & & & & & \\
\hline
\end{tabular}

*. The mean difference is significant at $<.05$.

**. The mean difference is significant at $<.01$.

Research question 3 tested how mobile learning affects student success online, measured by course grade and persistence to the next term. A Chi-Square Crosstab analysis was performed to analyze the association between the levels of mobile learning use with course grade and persistence to the next term. The overall analysis of mobile learning use levels and course grade levels did not show a significant association $\left(X^{2}=8.553, d f(10), p=0.575\right)$. The analysis of levels of mobile learning use with persistence to the next term also did not show a significant association $\left(X^{2}=12.786, d f(2), p=.242\right)$. The descriptive count tables for both course grade and persistence to the next term showed a lack of variance among the variables and low cell count for persistence to the next term. Overall, most students in the sample earned A and B grades and persisted to active enrollment for the next term.

\section{Discussion}

Among the initial questions on the survey, students were asked to identify which activities they engaged in while using a mobile device. Reading content had the highest percentage of use (90\%), participating on discussion boards was the following highest percentage of activity (75.3\%), watching videos was the third-highest percentage activity $(60.5 \%)$, and submitting work was the fourth-highest activity engagement while using a mobile device (40.7\%). Using a mobile device to take a test only occurred $31.5 \%$ of the time and using a mobile device to ask a question occurred the least at $26.5 \%$ of the time.

From the analysis results, mobile learning use has an impact on engagement. However, the effect is not the same for all groups and varies among the three SRL constructs tested. Previous research (Broadbent, 2017; Broadbent \& Poon, 2015; Puzziferro, 2008; Tabuenca et al., 2015) supports the assumption that time on task has a beneficial effect on student engagement and various measures of student success online. This current research also supports such findings and shows that the more students engage in mobile learning, the more they engage in selfdirected choices about managing time and managing task strategies. Examples of task strategies are working on extra problems, preparing questions ahead of time, and reading aloud to increase concentration. Examples of time management strategies used by self-regulated learners are engaging in the online course at regular and planned intervals, scheduling study time, and spacing study time across days.

Though the variation among the groups for the environment structuring construct was not statistically significant, the students in the sample engaged in environment structuring behaviors more than task strategies or time management strategies (Table 3). Considering these results and the significance of task strategies and time management strategies, it seems that choosing mobile learning may itself be a SRL behavior for these students. 
Table 3

\begin{tabular}{|c|c|c|c|c|c|c|c|c|}
\hline \multirow[t]{4}{*}{ (x) } & \multirow[t]{4}{*}{$\mathbf{N}$} & \multirow[t]{4}{*}{ Mean } & \multirow{4}{*}{$\begin{array}{l}\text { Std. } \\
\text { Deviation }\end{array}$} & \multirow{4}{*}{$\begin{array}{l}\text { Std. } \\
\text { Error }\end{array}$} & \multirow{2}{*}{\multicolumn{2}{|c|}{$\begin{array}{l}95 \% \\
\text { Confidence } \\
\text { Interval for } \\
\text { Mean }\end{array}$}} & \multirow[t]{4}{*}{ Minimum } & \multirow{4}{*}{ Maximum } \\
\hline & & & & & & & & \\
\hline & & & & & Lower & Upper & & \\
\hline & & & & & Bound & Bound & & \\
\hline Low & 70 & 16.96 & 2.590 & .310 & 16.34 & 17.57 & 12 & 20 \\
\hline Moderate & 55 & 17.31 & 2.340 & .316 & 16.68 & 17.94 & 12 & 20 \\
\hline High & 37 & 17.62 & 2.639 & .434 & 16.74 & 18.50 & 8 & 20 \\
\hline Total & 162 & 17.23 & 2.518 & .198 & 16.84 & 17.62 & 8 & 20 \\
\hline
\end{tabular}

The students in the low and moderate groups engaged in SRL at lower levels less than those in the high group. Nevertheless, most students in the sample earned grades of A and B in their course, and students in the low mobile use group earned grades of B more than any other grade. This might indicate that using a mobile device to access their courses was in addition to other types of access, such as laptops or desktop computers.

Two limitations of this study are the small sample size and the self-selection. The timing of data collection at the beginning of a term may not have appealed to less successful students discouraged by their recent lack of academic achievement. This would explain the lack of variance with the course grade and persistence data. However, the non-response bias for small sample size is reduced somewhat by the uniformity of the group, being all undergraduate online students at the same institution who are responding to a survey about that shared quality of the group (Bethlehem, 2010; Leslie, 1972).

\section{Recommendations}

This research can help improve practice in the realm of course design and online pedagogy. Online course design must consider the mobile learner to engage all learners and course users better. While many companies in the online learning marketplace offer numerous tips for making online learning content more mobile-friendly, very little research has been done to establish quality norms or best practices for mobile learning course design (Baldwin \& Ching, 2020). Knowing how students are engaging in Mobile Learning should inform how course designers incorporate mobile design. More research is needed to help develop the theory of Mobile Learning, which should inform the needed research on mobile learning course design.

Increased research on Mobile Learning should also improve online pedagogy. Current research suggests that many faculty members either do not consider that students use mobile devices as educational tools or faculty have false beliefs about student use of mobile devices (Gierdowski, 2019). Just as course design should consider the mobile learning user, so should content creation and teaching stance online. Knowing that students will be using a mobile device to engage with at least some of the course content should encourage faculty to ensure the content is compatible with mobile device users. From a pedagogical perspective, that could mean the choice to add short instructional videos to provide chunks of information in different formats. Even more simply, it could mean testing the mobile compatibility of a website before linking with course content. The more we know about mobile learning, the more we can purposefully expand pedagogy to include the experience of mobile learning users.

The disruption to the norms of higher education caused by the COVID-19 pandemic may be an opportunity for more meaningful consideration of Mobile Learning. Online learners may 
not have experienced disruption to their online learning environment, such as the students in this study. However, other disruptions in their lives may have caused an increased reliance on mobile devices. The sudden increase of hybrid and hyflex course delivery certainly brought mobile device use to the forefront over the recent academic year. As high school and college students gained more experience with their mobile devices as educational tools, they will expect to continue to be mobile in their college learning. Mobile learning offers great potential to reach a diversity of learners. Higher education must meet the demand for more mobile learning access and use. 


\section{References}

Alanazi, R. A., \& Brown, S. W. (2016). Online experience role in student's Self-regulation skills. Paper presented at the Northeastern Educational Research Association Conference. Trumbull, CT: NERA.

Baldwin, S. J., and Ching, Y. (2020). Guidelines for designing online courses for mobile devices. TechTrends: Linking Research and Practice to Improve Learning, 64 (3), 413-422. http://dx.doi.org/10.1007/s11528-019-00463-6

Barnard-Brak, L., Lan, W. Y., \& Paton, V. O. (2010). Profiles in Self-Regulated Learning in the online learning environment. The International Review of Research in Open and Distributed Learning, 11(1). https://doi.org/10.19173/IRRODL.V11I1.769

Bethlehem, J. (2010). Selection bias in web surveys. International Statistical Review, 78(2), 168188. https://doi.org/10.1111/j. 1751-5823.2010.00112.x

Broadbent, J. (2017). Comparing online and blended learner's Self-Regulated Learning strategies and academic performance. The Internet and Higher Education, 33, 24-32. https://doi.org/10.1016/j.iheduc.2017.01.004

Broadbent, J., \& Poon, W. L. (2015). Self-Regulated Learning strategies \& academic achievement in online higher education learning environments: A systematic review. The Internet and Higher Education, 27, 1-13. https://doi.org/10.1016/j.iheduc.2015.04.007

Capranos, D. \& Dyers, L. (2020). Online student behaviors and attitudes: A survey of prospective students, current learners, and recent graduates. Wiley Education Services. https://edservices.wiley.com/wp-content/uploads/2020/04/202404-Online-Student-Behaviorsand-Attitudes-Report-WES-Final-for-Web_x.pdf

Cheon, J., Lee, S., Crooks, S. M., \& Song, J. (2012). An investigation of mobile learning readiness in higher education based on the theory of planned behavior. Computers \& Education, 59, 1054-1064. https://doi.org/10.1016/j.compedu.2012.04.015

Cho, M-H., \& Shen, D. (2013). Self-Regulation in online learning. Distance Education, 34(3), 290-301. https://doi.org/10.1080/01587919.2013.835770

Dumford, A. D., \& Miller, A. I. (2020). Online learning in higher education: exploring advantages and disadvantages for engagement. Journal of Computers in Higher Education, 30, 452-465. https://doi.org/10.1007/s12528-018-9179-z

El-Hussein, M. O., \& Cronje, J. C. (2010). Defining mobile learning in the higher education landscape. Educational Technology \& Society, 13 (3), 12-21.

Gierdowski, D. C. (2019). ECAR Study of Undergraduate Students and Information Technology, 2019. EDUCAUSE. https://library.educause.edu/resources/2019/10/2019-study-ofundergraduate-students-and-information-technology 
Gikas, J., \& Grant, M. M. (2013). Mobile computing devices in higher education: Student perspectives on learning with cellphones, smartphones \& social media. Internet and Higher Education, 19, p.18-26. https://doi.org/10.1016/j.iheduc.2013.06.002

Grant, M. M. (2019). Difficulties in defining mobile learning: Analysis, design characteristics, and implications. Educational Technology Research and Development, 67, 361-388. https://doi.org/10.1007/s11423-018-09641-4

$\mathrm{Hu}$, S., \& Kuh, G. (2002). Being (dis)engaged in educationally purposeful activities: The influences of student and institutional characteristics. Research in Higher Education, 43(5), 555575.

Khaddage F, Müller, W., \& Flintoff, K. (2016). Advancing mobile learning in formal and informal settings via mobile app technology: Where to from here, and how? Educational Technology \& Society, 19(3), p.16-26. https://doi.org/10.1007/s10639-015-9400-x

Leslie, L. L. (1972). Are high response rates essential to valid surveys? Social Science Research, 1, 323-334.

Liu, Y., Hongziu, L., \& Carlson, C. (2010). Factors driving the adoption of m-learning: An empirical study. Computers \& Education, 55, p. 1211-1219.

https://doi.org/10.1016/j.compedu.2010.05.018

Magda, A. J., Capranos, D., \& Aslanian, C. B., (2020). Online college students 2020:

Comprehensive data on demands and preferences. Wiley Education Services.

https://edservices.wiley.com/wp-content/uploads/2020/06/OCS2020Report-ONLINE-FINAL.pdf

Martin, R., McGill, T., \& Sudweeks, F. (2013). Learning anywhere, anytime: Student motivators for m-learning. Journal of Information Technology Education: Research, 12, 51-67. https://www.learntechlib.org/p/111350/

Pew Research Center. (2021, April 7). Mobile Fact Sheet. Internet \& Technology. https://www.pewresearch.org/internet/fact-sheet/mobile/

Pintrich, P. R. (2004). A Conceptual framework for assessing motivation and self-regulated learning in college students. Educational Psychology Review, 16(4), 385-407.

Pintrich, P. R. (1999). The role of motivation in promoting and sustaining self-regulated learning. International Journal of Education Research, 31, 459-470.

Puzziferro, M. (2008). Online technologies self-efficacy and self-regulated learning as predictors of final grade and satisfaction in college-level online courses. American Journal of Distance Education, 22(2), 72-89. https://doi.org/10.1080/08923640802039024 
Rossing, J. P., Miller, W. M., Cecil, A. K., \& Stamper, S. E. (2012). iLearning: The future of higher education? Student perceptions on learning with mobile tablets. Journal of the Scholarship of Teaching and Learning, 12(2), 1-26.

Sha, L., Looi, C-K., Chen, W., \& Zhang, B.H. (2011). Understanding mobile learning from the perspective of Self-Regulated Learning. Journal of Computer Assisted Learning, 28, 366-378. https://doi.org/10.1111/j.1365-2729.2011.00461.x

Sharples, M., Taylor, J., \& Vavoula, G. (2016). A theory of learning for the mobile age. In Haythornthwaite, C., Andrews, R., Fransman, J., Andrews, R. N. L., and Meyers, E. M. (Eds.). SAGE Handbook of E-Learning Research. (2 ${ }^{\text {nd }}$ ed., pages 63-81). SAGE.

Tabuenca, B., Kalz, M. Draschler, H., \& Spect, M. (2015). Time will tell: The role of mobile learning analytics in self-regulated learning. Computers and Education, 89, 53-

74. https://doi.org/10.1016/j.compedu.2015.08.004

Vázquez-Cano, E. (2014). Mobile distance learning with smartphones and apps in higher education. Educational Sciences: Theory and Practice, 14(4), 1505-1520.

https://doi.org/10.12738/estp.2014.4.2012

Vilkanos, R., Bakanoviene, T., \& Turkiene, S. (2013). Readiness of adults to learn using elearning, m-learning, and t-learning technologies. Informatics in Education, 12(2), 181-190. Zimmerman, B.J. (2008). Investigating self-regulation and motivation: Historical background, methodological developments, and future prospects. American Educational Research Journal, 45(1), 166-183.

Zimmerman, B.J. (2001). Theories Of Self-Regulated Learning and Academic Achievement: An Overview and Analysis. Routledge. 